\title{
Chilean Children's Reading Levels of Statistical Graphs
}

\author{
Danilo Díaz-Levicoy ${ }^{1}$, Carmen Batanero ${ }^{2 *}$, Pedro Arteaga ${ }^{2}$, María M. Gea ${ }^{2}$ \\ ${ }^{1}$ Universidad Católica del Maule (UCM), Talca, CHILE \\ 2 University of Granada, SPAIN \\ *CORRESPONDENCE: $\square$ batanero@ugr.es
}

\begin{abstract}
The aim of this research was comparing the performance of primary school Chilean children when reading different types of graphs included in the primary school curriculum in this country (pictogram, line graph, pie chart and dot plot). A sample of $7456^{\text {th }}$ and $7^{\text {th }}$ Grade students were given a questionnaire including four tasks in each of which they should perform a critical reading of one of these graphs. The analysis of the children written responses to the questionnaire served to compare the tasks difficulty when measured by the percentage of correct responses and to study the reading level achieved in the children's responses using the classification of Curcio and his collaborators. Globally, the children obtained $60 \%$ or more correct responses except when reading the pie chart that was the most difficult task, probably because of the need of proportional reasoning, which is still developing at this age. Few children succeeded in attaining the critical reading level N4 in their responses, although most of them achieved the reading level N2, which implies not only a literal reading, but also the ability to compare the data or perform computations with the same.
\end{abstract}

Keywords: statistical graphs, children reading levels, primary education

\section{INTRODUCTION}

A relevant part of the information we face every day in the media is given in statistical graphs, whose interpretation is often needed to make different decisions in almost all areas linked to everyday and professional life. Therefore, there is a need for citizens to achieve enough graphical competence to manage in the information society (Ridgway, 2016). According to Aoyama (2007), citizens are increasingly dealing with statistical information presented through different graphs and an important role of statistical education in the 21st century is that citizens are able to ask critical questions about the information represented through graphs and obtain conclusions about this information.

The study of statistical graphs has been relatively recently included in the primary school curricula around the world (e.g. in MEC, 2006; MEP, 2012; NCTM, 2000). With this incorporation these curricula recognize the relevance of graphical competence that is today needed, due to the wide availability of graphs and data of social interest for all citizens (Engel, 2019). However, as suggested time ago by Friel, Curcio \& Bright (2001), we still have much to learn about the processes involved in reading, analyzing, and interpreting information presented in graphs. Although graphs apparently make information easy to understand, many studies have proved that their interpretation can be effortful and error-prone (Freedman \& Shah, 2002).

More specifically, in Chile, children are requested to collect and record data to answer statistical questions about themselves and their environment, using bar charts, tables and pictograms, as well as to read and interpret these representations since the 1st Grade. In particular (MINEDUC, 2012), there is an explicit

Article History: Received 24 April $2019 \bullet$ Revised 10 May $2019 \bullet$ Accepted 12 May 2019

(C) 2019 by the authors; licensee Modestum Ltd., UK. Open Access terms of the Creative Commons Attribution 4.0 International License (http://creativecommons.org/licenses/by/4.0/) apply. The license permits unrestricted use, distribution, and reproduction in any medium, on the condition that users give exact credit to the original author(s) and the source, provide a link to the Creative Commons license, and indicate if they made any changes. 
reference to the work with the following types of graphs in the topic on Data and probability: pictograms (Grades 1-4), bar graph (Grades 2-5), dot plot (Grades 3 and 6), line graphs (Grade 5), stem and leaf diagrams (Grades 5 and 6) and pie chart (Grade 6). Moreover, these guidelines are reproduced in the textbooks, as shown in the study by Díaz-Levicoy, Batanero, Arteaga and Gea (2016).

These educational changes in the curricula should go along with research into the children's competence to accomplish the suggested task and to understand the underlying concepts. According to Freedman and Shah (2002), a fundamental question is the characterization of the graph comprehension processes and of the characteristics of tasks that help these interpretation processes. Although research that focusses on the children ability to read statistical graphs and on the level of complexity of the graphical tasks that can be proposed to the children is recently increasing, the studies centering in the performance of Chilean children in these tasks is almost inexistent; this research is needed to help the teacher to organize the classroom practice.

Given the above reasons, in our research we are interested in the Chilean children competence in interpreting different graphs included in the school curricula and in the reading level shown in the children responses when reading these graphs. Below we describe the research background and method, present our results and discuss our conclusions.

\section{GRAPH READING LEVELS}

Reading a graph is a complex activity that requires interpreting each element (title, scales, labels, geometric elements), as well as the graphic as a whole (Arteaga, Batanero, Contreras, \& Cañadas, 2012; Tufte, 2001). Curcio (1987) considered the following elements in a graph:

- The different words that appear in the title, the axis labels and the scales. Each of these words provides the keys needed to understand the context of the data, the variables that have been represented and the relationships between these variables expressed in the graph.

- The underlying mathematical content embedded in the graph, which student should know to interpret correctly the graph. For example, integer numbers and their representation in the number line, to interpret the scales; area in a pie chart, length in a bar graph, area in a histogram or Cartesian coordinate in a scatter plot.

- The specific conventions used to build each graph that need to be known to make a correct reading or construction. For example, the student must know that in a pie chart, the circular sector is proportional to the frequency of each category or that, in scatter plots, each point represents one case and the coordinates the values of the two variables represented.

Understanding statistical graphs involve composing individual data values into an aggregate or distribution and perceiving this distribution as a whole; however, some students only perceive graphs instead as "collections of values" (Konold, Higgins, Russell, \& Khalil, 2015). The reason is that reading a graph is a complex activity where different interpretative processes as needed, according to Bertin (1967):

- Establishing an external identification between the conceptual and real world elements represented in the graph; this step help in finding information about the variables represented, the data source, the purpose of the graph, the size of the sample or population, etc.

- Performing an internal identification of the variability in the different dimensions considered in the graph (the scales selected and how they would translate to the real situation, as well as the range of variation of the variables).

- Identifying a correspondence between each element of the graph and the represented reality. This leads to conclude about the variables, their distribution and characteristics, as well as the relationship between the variables in the real situation represented.

Following this theory, different authors have defined levels in reading the graph, because for the same graph it is possible to pose questions of different difficulty. In our study, we use the reading levels introduced by Curcio and his collaborators (Curcio, 1989; Friel et al., 2001) and by Shaughnessy, Garfield and Greer, 1996):

N1. Reading the data, where only the literal reading of an element of the graph is required and involves the compression of specific aspects of the graph. For example, in a bar graph, a reading level N1 
question is when you ask the child to identify the variable represented in the Y-axis; to solve this question, the child only needs to read the title associated with the axis.

N2. Reading between the data. Besides the literal reading of the graph, in this level the child has to perform comparison of various data represented in the graph or performing some arithmetical calculations with the same. For example, child is asked to obtain the mean or mode in a distribution represented in a graph. This level is particularly important for interpreting graphs over time, that is, for detect tendencies in a graph.

N3. Reading beyond the data. This level involves obtaining or predicting information that is not directly represented in the graph, which requires the interpolation or extrapolation of the information shown. For example, from a graphical representation of data corresponding to six consecutive years, the child is asked to predict the value of the variable represented in the next year.

N4. Reading behind the data. A child attains this level when he or she is able to make a critical valuation of the graph, of the way it has been constructed or he can discuss a statements related to the graph content. An example of this level is discussing the truth or falsity of an assertion, using the information represented in the graph.

A different approach was taken by Aoyama (2007) who used the SOLO taxonomy () to describe the ability to read graphs in 142 12-19 year olds students and 22 undergraduates (22 year olds or older). In her classification level 1 (idiosyncratic) implies no ability to read the graph, level 2 (basic graph reading) is equivalent to Curcio's level N2 and level 3 (rational/literal) is equivalent Shaughnessy et al level N4. She also expand with two upper levels: In level 4 (critical) where students can evaluate the reliability of the context meaning described in the graph; and in level 5 (hypothesizing and modelling) students can form their own explanatory hypotheses about the information on the graph. We only consider questions up to level 3 in Aoyama' classification, given the age of children in our research.

\section{RELATED RESEARCH}

The interest in the levels that children can achieve when reading a graph started with the work by Curcio (1981), who studies the relationship of various variables on the understanding of statistical graphs, among which, she considered the pictogram, bar graph, line graph and pie chart. The author proposed six multiplechoice questions, two from each level N1 to N3 previously described to a sample of 204 fourth-grade students and 185 seventh-grade students in American schools. Curcio found a statistically significant effect of age and mathematical knowledge (measured by the child's average scores in previous courses) on children performance in the tasks; however, she did not provide information on the percentage of children reaching the different reading levels in each of the graphs.

Pagan, Leite, Magina and Cazorla (2008) studied the reading of statistical tables and graphs by 399 students (159 of fifth-grade and 80 eight-grade students in Primary Education and 160 second-grade students of Secondary Education) in Brazil. In two of the items, related to bar graphs, their data showed an achievement of $67.3 \%$. The authors obtained better results in the activities that demanded a reading level N1 ( $84 \%$ of correct answers) versus $43 \%$ in the activities requesting a reading level N2.

Canché (2009) applied a multiple-choice questionnaire, with questions of different reading levels in Curcio (1989) classification to 206 sixth-grade students in Mexico. The percentage of correct answers ranged between $19.4 \%$ and $82 \%$ according to the item in N1 and N2 levels questions, and between $22.3 \%$ and $79.6 \%$ level N3 tasks.

Albuquerque (2010) posed several tasks to analyze adults and fifth-grade children's understanding of the scale in a graph. One of her tasks is used in our research (task 2) and the author informed that $43 \%$ children selected the correct graph, although the reasons to justify the responses were not always valid. The author does not inform about the reading levels in the different responses.

Fernándes and Morais (2011) analysed the responses by 108 ninth-grade students to three activities related to the reading of graphs (bar graph, pie chart and line graph). They got $68 \%$ of correct answers to questions of level N1, 33\% to level N2 and $24 \%$ to level N3 questions. In the bar diagram, $90 \%$ of students reached $\mathrm{N} 1$ and $23 \% \mathrm{~N} 2$. In the pie chart, $96 \%$ achieved N1, 31\% N2 and 23\% N3. In the line graph 19\% of children obtained N1, $14 \% \mathrm{~N} 2$ and $43 \% \mathrm{~N} 3$. 
Pagan and Magina (2011) studied 105 ninth-grade students in Brazil, applying a pre-test, a classroom intervention and a post-test. The post-test presented two activities related to the reading of graphs (bars and lines graphs) and one in which the information should be translated from a graph to a table. $42.3 \%$ of the students correctly solved the reading activities and $42 \%$ the translation tasks. Regarding Curcio's reading levels, $67 \%$ of students correctly read a question of reading level N1, and $42 \%$ of students achieved the level N2 and $18.7 \%$ of students the level N3 activities. The results showed an improvement in the three groups after the classroom intervention.

Cruz (2013) described an instruction process related to statistical tables and graphs with 21 third-grade children in Portugal. At the end of the teaching, Cruz applied a questionnaire, where $82 \%$ of the children correctly completed the reading activities of level N1, 70.5\% reached level N2 and $66.5 \%$ of them could perform the level N3 activities.

Evangelista (2014) studied the performance of 60 fifth-grade students in Brazil when working with bar and line graphs using eight activities of reading levels N1 and N2. The students correctly answer 51\% of the activities proposed. The best results were achieved in the bar graphs and the lowest results in the double line diagram. On average, the students correctly answered 59\% of activities related to bar charts and $43 \%$ of line charts. On the type of question, the reading of frequencies or categories had an achievement of $60 \%$, followed by locating the mode with $51 \%$ and finding the sum of values with $41 \%$.

None of this research has dealt with Chilean children. To fulfil this gap, in Batanero, Díaz-Levicoy and Arteaga (2018) we gave a questionnaire to a sample of 745 Chilean primary school children who were asked to translate data from a pictogram to a table and to discuss a statement based on data from another pictogram. In the first task where there was only possible to reach level N2, most children (93\%) reached this level, while in the second task aimed to evaluate the critical reading (level N4) most children only stayed at level N2.

In this new research, we expand Batanero et al. (2018) research and compare the children performance and the reading levels in three additional tasks related to other types of graphs. While in the previous research, including that by Batanero et al., the maximum reading level that is possible to achieve varies in different items in this new study the reading levels that are possible to achieve are the same $(1,2$ and 4$)$ in all the items. This will help to compare the maximum level obtained in each task, as well as the percentage of correct responses to the same, which will be an original contribution of this research.

\section{METHOD}

A total of Primary Education 745 students in Chile (380 sixth-grade children (11-12 year-olds) and 365 seventh-grade children (12-13 year-olds)) took part in the sample. These students were recruited from 13 public schools or private schools of different cities of Chile (Osorno, Castro, Queilen, Puerto Octay, La Union, Viña del Mar and Nuñoa), in order to achieve greater geographical representativeness, type center and socioeconomic characteristics of the participating children. The centers collaborated on the research, after receiving permission of the educational authorities, center directors and classroom teachers.

\section{Tasks Analyzed}

The children were given the questionnaire displayed in Figure 1, in each of which the children can achieve to a maximum reading level N4 (critical reading), as they are requested to discuss different sentences with base on the information extracted from the graph. All the tasks have been adapted from similar exercises include in the primary school textbooks in Chile or from previous research with children. The graph varies in the different tasks (pictogram, line graph, pie chart and dot plot in tasks 1 to 4 respectively). In tasks 1 and 4 , the children should explain why they agree or do not agree with a sentence (which is incorrect for task 1 and correct for task 4). In tasks 2 and 3, the children should select the most appropriate graph for a specific purpose: visualizing better the advantage of a candidate in a voting survey in item 2 and representing exactly the information given in a table in item 3 . There is no numerical scale in task 1 , where children should identify the row corresponding to science books, count the number of icons in that row (two) and multiply this amount by 15 to obtain 30 science books, since each icon corresponds to 15 books. The mathematical concepts underlying the task are only qualitative variable and category, integer number, counting and multiplication. This task was adapted from a Grade 3 textbook (Charles et al., 2014, p. 253). 
Task 1. The school librarian performed an inventory in the library and displayed the results in this graph. A child said that there are only two science books in the library. Is the child right? Why or why not?

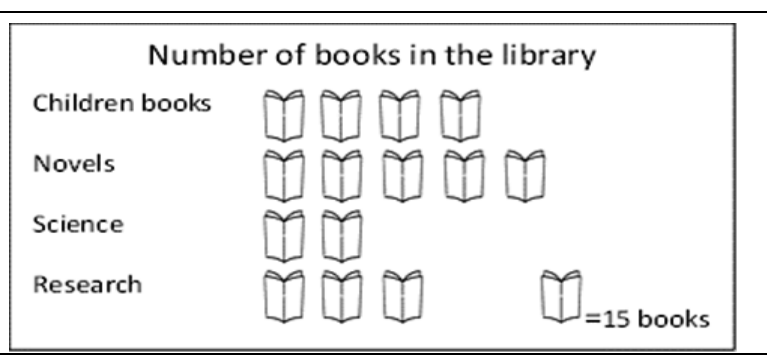

Task 2. These two graphs show the same results of a voting survey. If you were Pedro, which graph would you prefer? Why?
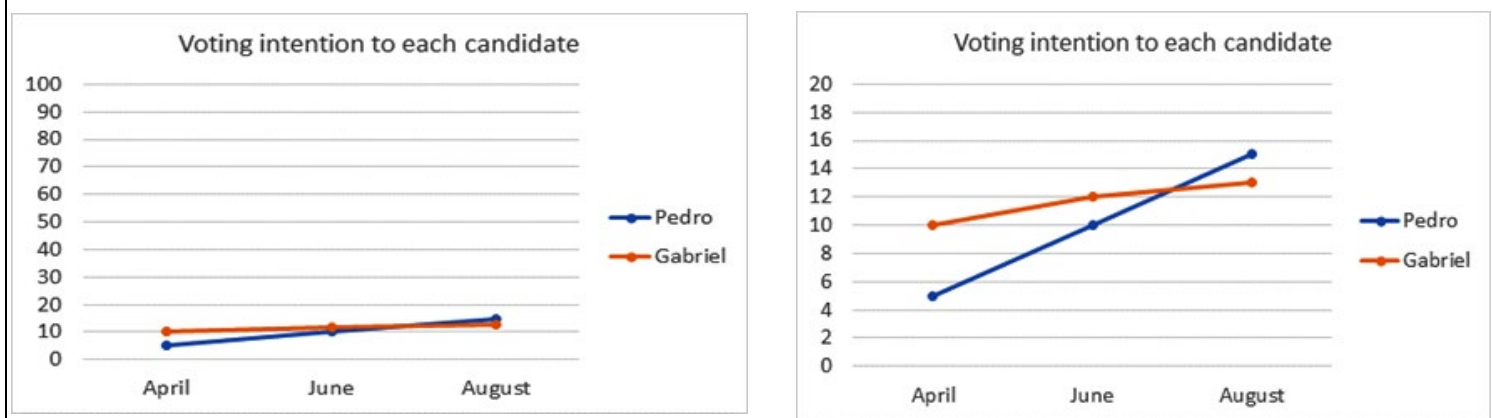

Task 3. The following table shows the number of children in school practicing various sports. Which graph corresponds to the information given in the table? Why?

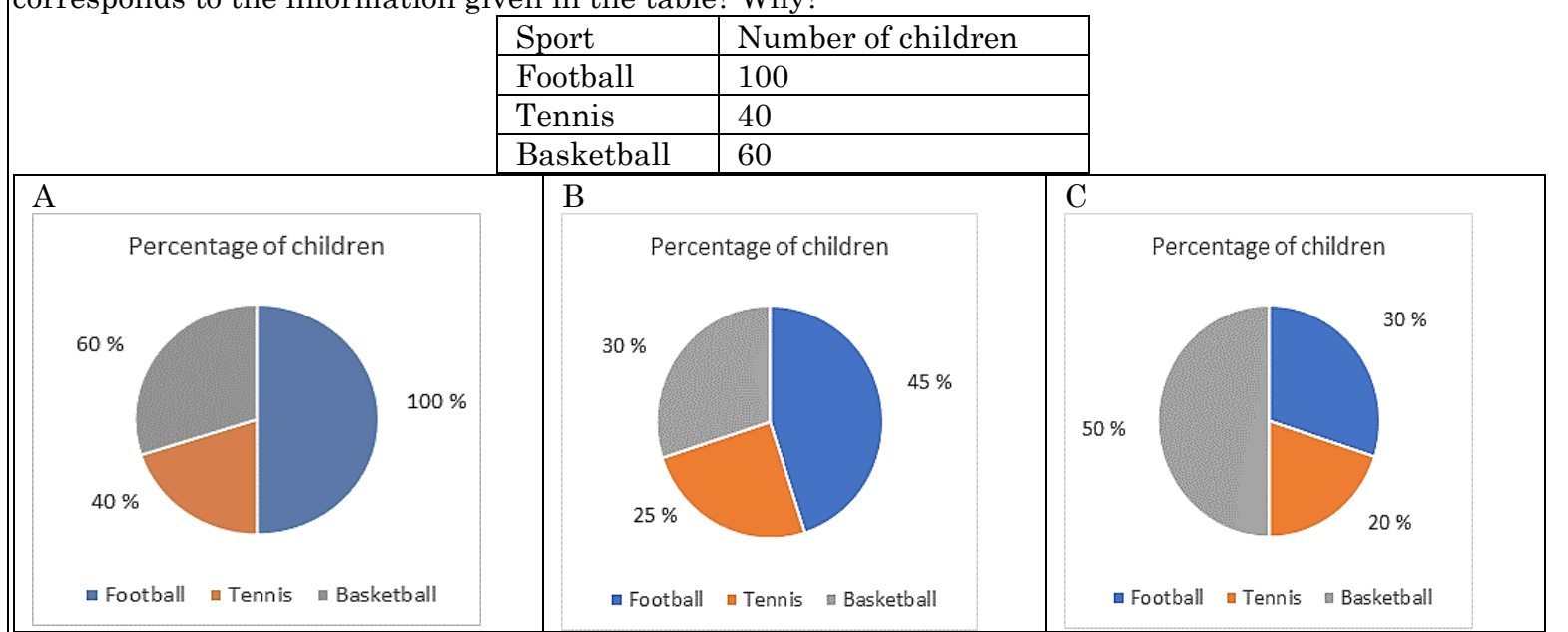

Task 4. In the following graphs we represent the language and mathematics scores of some children. Maria suggests that Mathematics is more difficult, as there are fewer children with 6 or more points. Do you agree with Maria? Why or why not?
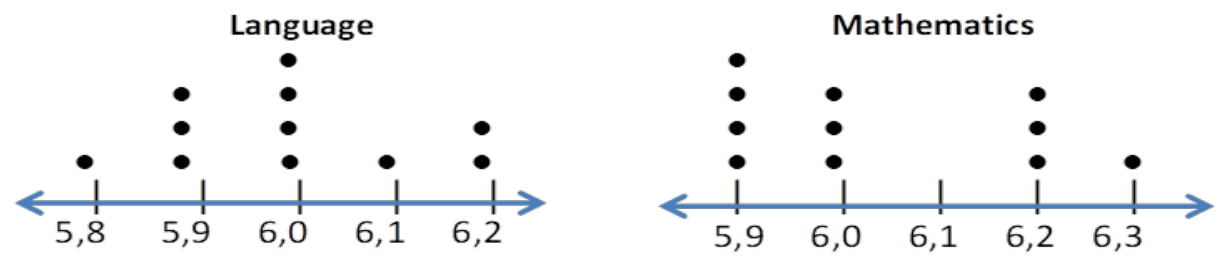

Figure 1. Questionnaire given to the children

In task 2, adapted from Albuquerque (2010), the same data are represented on line graphs using two different numerical scales for the Y-axis: 0-100 for the left hand side diagram and 0-20 for the right hand side diagram. The rising in the voting percentage of the candidate Pedro from April to August is much more visible on the right hand side diagram and then we expect that children select this diagram. The mathematical concepts underlying the item are numerical variable and value, segment, angle (of the segment with the 
Table 1. Percentage of correct responses to the different tasks

\begin{tabular}{lcc}
\hline Task & Grade $\mathbf{6}(\mathbf{n}=\mathbf{3 8 0})$ & Grade $\mathbf{7}(\mathbf{n}=\mathbf{3 6 5})$ \\
\hline 1. Pictogram & 65.6 & 61.1 \\
\hline 2. Line graph & 64.5 & 60.5 \\
\hline 3. Pie chart & 31.3 & 38.4 \\
\hline 4. Dot plot & 59.7 & 59.2 \\
\hline
\end{tabular}

horizontal axis), integer numbers and interpretation of a numerical scale. In task 3, designed for this research, the children should remember that in a pie chart the circular sectors are proportional to the frequency in each category. Since the title of the graphs indicates that the data are given in percentages, the children should read the table, and convert the absolute frequencies displayed on the table to percentages and then identify the correct pie chart $\mathrm{C}$. On the graph A, the percentages do not add to 100, while on the graph B the percentages are incorrect. The mathematical concepts implicit in the task are qualitative variable and category, frequency, circle, circular sector, angle, proportion, percentage.

In task 4, adapted from a Grade 6 Chilean textbook (Ávila et al., 2013), the children should understand the meaning of the sentence "6 or more points", and identify the values that fulfill the sentence on the numerical horizontal axis. Then, they should count the number of points corresponding to 6 or more, to finally discover that Maria is wrong, as the number of children with scores 6 or more are the same for the both subjects. The mathematical underlying concepts are numerical variable and value, decimal numbers and frequency.

The children completed the questionnaire as an activity in the mathematics classroom, where their teacher and one of the researchers assured that they understood the questions and they completed the questionnaire with interest. We performed a content analysis of the written responses to determine two variables: a) the correctness or incorrectness of the response; b) the reading level achieved by the children in justifying their responses. Content analysis is a systematical research method that helps making replicable and valid inferences by interpreting and coding textual material (Neuendorf, 2016). It is used with text (in our research the written responses of students) that are converted into quantitative data. For each task the responses were classify and compared in order to produce the analysis categories that were refined by an inductive procedure typical of qualitative research. In this way, we could classify the responses according correctness and according reading level.

Below, we first report on the tasks difficulty that was measured by the percentage of correct responses and then describe the reading levels in the different tasks.

\section{RESULTS}

\section{Task Difficulty and Main Errors}

In Table 1 we present the percentage of correct responses to the different tasks, where we classified the response as correct when the children reasoned according to the solution we exposed in the analysis of tasks.

A response in task 1 is correct when the students suggest that Maria (the imaginary child) was wrong, since there are two icons in the row corresponding to science book and each icon represents 15 books, such as, in E38 response below. An incorrect typical response is counting each icon and replying that Maria is right. In this case the child fails to interpret the code that each icon accounts for 15 books.

E38 in task 1: False, since as you can see each picture counts for 15 books and there are two pictures for science books; then if you add $15+15$ you get 30 books.

In task 2, a correct response implies that the child correctly reads the title and the scales of both graphs, understand the context of the situation and the meaning of the labels in the X-axis (months, where different voting surveys were repeated). The child should select graph B because in this graph the increase of votes for the candidate is amplified by the change in the vertical scale, as suggested in the following correct response:

E705 in task 2: Peter should use graph B, since the rank of Y-axis is smaller and there is a visual difference.

An incorrect response in task 2 consists in not being able to make a decision about which graph should be selected. In task 3, the student should transform the data in the table to percentages, read the labels in the 
graphs and compare the percentages in each category with his or her computations. Since half the children in the situation play football, the correct graph is C. In selecting graph A, students confuse frequency and percentage and in graph B they fail to compute the percentages. An example of correct response is given below:

E22 in task 3: If you look to the table, there are 200 children, so to obtain a $100 \%$ you have to divide each number by 2 and you get: 100/2=50\% football, 40/2=20\% tennis and $60 / 2=30 \%$ basketball.

In task 4 (comparing two numerical distributions represented in dot plots), a correct response implies that the child first identifies the numerical values equal or higher than $6(6,6.1,6.2,6.3)$, then the students counts the number of dots for each of these values, obtain the frequencies for the set of values in both graphs, and finally compare these frequencies to answer the question, as in the following example:

E700 in task 4: I do not agree, since in language and mathematics there are 7 children with 6 or more; and even in mathematics there are more children with 6.2 and a child with 6.3.

Most incorrect responses in task 4 consist in comparing only parts of the graphs, for example, only the maximum or minimum values.

As displayed in Table 1, most children provided correct answers to all the tasks, except by task 3, corresponding to the pie chart. The percentage of correct responses was a bit higher in sixth-grade children in the two first tasks, and lower in the third task; however the differences in percentage were not statistically significant.

Results in the reading of a pictogram were a bit worse than those obtained by Cruz (2013) who got 70\% of correct responses in reading this graph with third-grade children; however in her pictograms each icon only counted by 1 element, and therefore our task is more complex. As regards the comparison of two line plots (task 2) results outperform those by Evangelista (2014), who only got 43\% correct responses in the reading of a double line graph; even when our task is more complex as it involves comparison of two double line graphs and the maximum reading level is N4, while in Evangelista was N2. Our results were also better than those by Albuquerque (2010) with fifth- grade students (43\% of correct selection of the graph, in the same task).

In the selection of a pie chart, (task 3 ) results were poor as only about a third of students succeeded in the correct computation of percentages to identify the correct graph, with better results in the older students who have better proportional reasoning. Fernándes and Morais (2011) got 45\% of correct responses in reading pie chart, although they only considered the reading level N1 and N2, while, in a level N1 task, Cruz (2013) obtained $70 \%$ of correct responses in pie charts. Finally, when comparing two numerical distributions represented in dot plots (task 4), the results were very similar in both groups and most students got a correct response. We found no previous results to compare with our results in this task.

In order to provide a numerical indicator of the correctness of children responses, we assigned a score of 2 points per each correct response in questionnaire and 1 point to those children who made an attempt but either failed or the response was only partly correct. In Figure 2, we display the distribution of these scores in both groups of students. We perceive no difference in the medians, since, on average, each child provided 3 correct responses to the 4 tasks (and then got 6 points), which is a very good result. There is more variation in the seventh- grade children, as shown in the values below the median and the first quartile, which is lower in these students. 


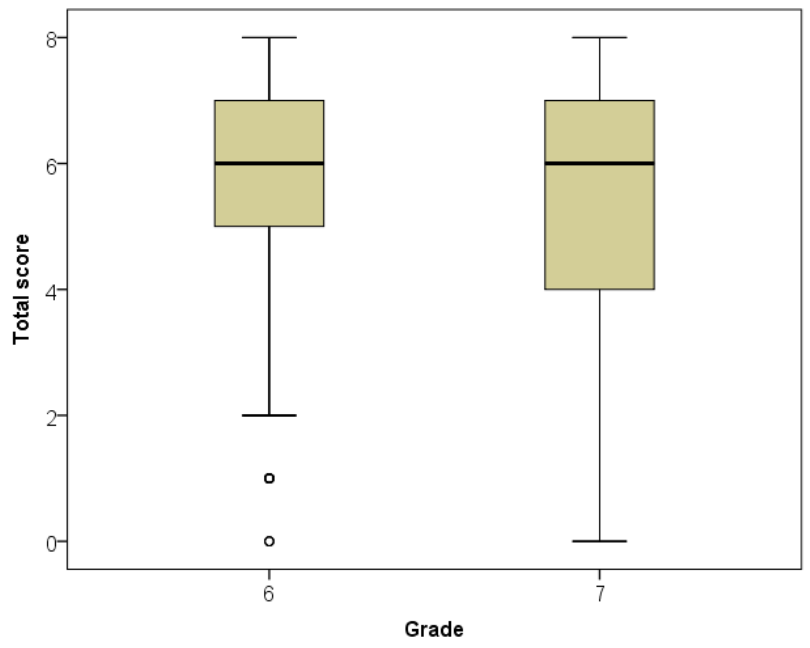

Figure 2. Distribution of the total score by grade

\section{Reading Levels}

Next, we analyzed the reading level reached by the student in their justifications. These justifications were classified according to the reading levels of Curcio et al. (Curcio, 1989; Friel et al., 2001; Shaughnessy et al., 1996), described above, and were interpreted as follows:

Level 0 . When the information requested in the question is not read or the reading of the graph is incorrect.

Level 1. Reading the data. When the student correctly makes a simple reading of a data in the graph. For example, in task 1, E55 correctly counts the number of icons in the science row, although he does not realize that each icon counts for 15 books. In task 2. E441 was able to read the months in the horizontal scale in the graph, but did not perform any comparison between both graphs or into one of the graphs. In task 3, E38 correctly read the frequency of children practicing each sport in the table and could identify the same quantities on the first graph; however, he selected a wrong graph because he confused frequencies and percentages. In task 4, E17 was able to correctly read the number of points corresponding to a score of 6 in mathematics.

E55 in task 1: True, because in the inventory row for science books there are two books

E441 in task 2: Pedro will select a graph on August.

E38 in task 3: I chooses graph A because it represents the amount displayed on the table where 100 children play football, 40 of them play tennis and 60 of them basketball

E17 in task 4: There are three students with a score of 6.0 in mathematics.

Level 2. Reading between the data. When the affirmation is correctly answered, and therefore, apparently, the student has correctly read the graph. In addition, the student made some computations or comparisons with the same; however, he or she does not reach the critical reading level because he or she is unable to provide a correct argument to support the response. For example, in task 1, E21 has correctly found that there are 30 science books in the library, and then this student found the row corresponding to science books, counted the number of icons and multiplied this number by 15, as suggested in the graph, but the students did not provide an argument to justify the response. In task 2, E17 selected the correct graph and moreover perceived the increasing tendency in Pedro's data; however, the argument is not convincing as Gabriel's data also rise and, moreover, there is no mention to the effect produced in the graph by the change of scale. In task 3 , A27 correctly identified the correct graph and suggested this graph is correct because the percentages add up to 100; consequently, this child has not only read the graph data, but has performed some computation with the same. Again, his argument is not convincing. Finally, in task 4, E479 succeeded in reading some data of the graph and making some comparisons; in fact he compared the maximum and minimum scores in the graphs; however the argument is incorrect since the comparison is only based on part of the data. 
Table 2. Percentage of children achieving the different reading levels in each task

\begin{tabular}{ccccccccc}
\hline & \multicolumn{2}{c}{ Task 1 } & \multicolumn{2}{c}{ Task 2 } & \multicolumn{2}{c}{ Task 3 } & \multicolumn{2}{c}{ Task 4 } \\
\hline $\begin{array}{c}\text { Reading } \\
\text { level }\end{array}$ & $\begin{array}{c}\text { Grade 6 } \\
(\mathbf{n = 3 8 0 )}\end{array}$ & $\begin{array}{c}\text { Grade 7 } \\
(\mathbf{n = 3 6 5 )}\end{array}$ & $\begin{array}{c}\text { Grade 6 } \\
(\mathbf{n = 3 8 0 )}\end{array}$ & $\begin{array}{c}\text { Grade 7 } \\
(\mathbf{n = 3 6 5 )}\end{array}$ & $\begin{array}{c}\text { Grade 6 } \\
(\mathbf{n = 3 8 0 )}\end{array}$ & $\begin{array}{c}\text { Grade 7 } \\
(\mathbf{n = 3 6 5})\end{array}$ & $\begin{array}{c}\text { Grade 6 } \\
(\mathbf{n = 3 8 0 )})\end{array}$ & $\begin{array}{c}\text { Grade 7 } \\
(\mathbf{n = 3 6 5})\end{array}$ \\
\hline 0 & 1.8 & 1.4 & 29.2 & 31.8 & 17.6 & 21.4 & 45 & 49.3 \\
\hline 1 & 35.5 & 39.2 & 5.8 & 4.4 & 49.5 & 38.9 & 6.6 & 3.3 \\
\hline 2 & 56.1 & 53.2 & 53.4 & 47.9 & 25 & 28.5 & 47.4 & 46 \\
\hline 4 & 6.6 & 6.3 & 11.6 & 15.9 & 7.9 & 11.2 & 1.1 & 1.4 \\
\hline
\end{tabular}

E21 in task1: False, there are 30 science books.

E17 in task 2: The right-handed graph because Pedro is increasing.

E 27 in task 3: C. Because it is the only graph that gives 100 when adding the numbers.

E479 in task 4: I do not agree because in language, the lowest Grade was a 5.8 and in mathematics the highest Grade was a 6.3.

Level 3. Reading beyond the data. This level is not considered in the tasks since any predictions or extrapolations are requested from the graph data.

Level 4. Reading behind the data. When the answer given by the student implies, in the first place, the correct reading of the graph as well as the performing of the calculations needed to reply the task. In addition, the student reaches a critical reading level according to Shaughnessy et al., (1996), because he or she is able to determine whether the statement is correct or not and can also give an argument in this regard. In our research the questions posed at this level correspond to level 3 (rational/literal) in Aoyama (2007) research.

In our first example, E38 reads correctly the data in task 1 and multiply the number of icons by 15 ; finally the student provides a correct argument to justify the response. In task 2, E125 is not only able to correctly read both graphs, but to determine and compare the tendency of both candidates in the two graphs and appreciate the visual effect of changing the scale in the second graph. In task 3, E122 has computed the percentage of children practicing the different sports, after reading the data and has identified the graph that correctly represents these percentages. Moreover, he provided a correct argument to justify that the percentages in the other graphs are incorrect. Finally, in task 4, E42 read the graph and performed different comparison between the frequencies corresponding to various values in the mathematics and language scores. These comparisons include the maximum, the number of children with scores over 6 or equal and higher than 6.

E38 in task 1: False, since as you can see each picture counts for 15 books and there are two pictures for science gooks; then if you add $15+15$ you get 30 books.

E125 in task 2: When comparing the graphs I noticed that in graph A both candidates looks like they had almost the same votes, but in graph B changes everything, since when decreasing the counting the votes two by two Pedro appears as he would be winning and that is why he would select graph B.

E122 in task 3: C. Because the total number of children practicing sports is 200 and half of them are 100, but there are also 100 children playing football, so in the graph football should be $50 \%$ to be correct. In addition, the total percentage is $100 \%$, as required, but in graph A the total percentage is $200 \%$ and this is incorrect.

E42 in task 4: I do not agree since the same number of scores 6,0 or higher; besides the worst mathematics score is 5,9 while in language the worst score is 5,8 [;] also there are more children with scores higher than 8 in mathematics on 6 than language and the best score is 6.3 higher than in language $(6,2)$.

As displayed in Table 2, few students attained the upper critical reading level in the different graphs, what suggest that this type of task is too difficult for sixth and seventh grade children. Although there were a few more seventh grade children achieving level N4 in task 2 and 3, there were no difference in the other tasks (providing an argument to reject a statement based on the data in a graph and comparing the graphs of two 


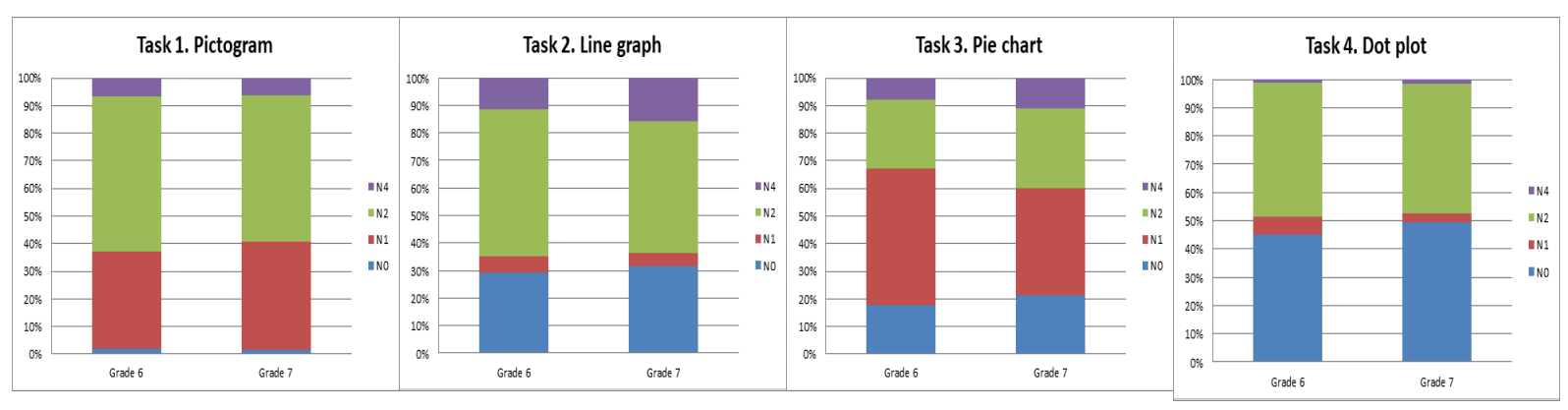

Figure 3. Reading levels in the different tasks

numerical distributions). In Aoyama (2007) research only 15\% or 12-13 year-olds students (one year older than ours students) reached this level.

In task 1 (discussing a sentence based on reading a pictogram) the most frequent reading level was level $\mathrm{N} 2$, because most children not only read the number of icons corresponding to science books, but computed the amount of books that corresponded to the number of icons. This percentage is higher than that of children reaching level N2 in reading a pictogram in Cruz (2013) research (46.8\%), although these students were younger. However, an important percentage of children still limited to count the number of icons without translating the icons to frequencies and stayed at reading level N1.

In task 2 (comparing the effect of changing the scale in a line graph) the most frequent reading level was also level N2, because many children not only read the graphs but also were able to detect the tendencies in the same. Moreover, part of the children observed the influence of changing the scale on the graphs and provided sound arguments to justify the election of a graph, in particular in the older students. However, many students also failed in even reading the graphs and did not provide a sound response to the task. We remember that Evangelista (2014) only achieved correct responses in the reading of double line graphs in $41 \%$ of fifth grade students, so that our results are somehow better.

In task 3 (identifying the pie chart that correspond to given data), the most frequent reading level was level N1 because many students confuse frequencies and percentages or had problems in computing percentages. The proportion of students unable to read the graphs or that reached level N2 was very similar. In this regards we remember that Cruz (2013) only got $23 \%$ of students providing good responses in the reading of pie charts, although Fernández and Morais (2011) got 96\% of their students achieving level N1 in the pie chart and $31 \%$ attaining level N2.

Finally in task 4 (comparing two numerical distributions represented in dot plots) the students were divided between not reading the graph and attaining reading level N2, because most of those who were able to read the graph were able to make some comparison of the data, although not all the comparisons needed to answer successfully the task.

The difference in reading levels in the various tasks are more visible in Figure 3, where it is clear that the critical reading level N3 is hardly achieved, especially when reading the dot plot, while there is a higher proportion in the reading of line graphs. The reading level N2 is attained by a majority of children with exception of task 3 where proportional reasoning failed in many of them and for this reason there was a majority of children below this level. We also notice the high proportion of children that do not reach a simple reading level N1 in the dot plot.

\section{IMPLICATIONS FOR RESEARCH AND PRACTICE}

Our research complemented other studies focusing in the reading levels of statistical graphs that children are able to reach when finishing the primary school. On the one hand, we proposed to the children different tasks, where they were requested to perform a critical reading of the graph, that is, where the maximum reading level is level N4, while none of the previous studies proposed this type of activity to their children. For this reason, our information related to the percentage of children who could attain this level and the examples of the types of responses expected in those who succeed in a critical reading of the graphs is an original contribution to our knowledge of the graphical competence of children of these ages. 
Although apparently the children in our sample failed in this type of tasks, given the small percentages that are able to reach this level in our study, we draw the attention that these types of activities are sometimes found in the schoolbooks, as suggested in the study of Batanero, Díaz-Levicoy and Arteaga (2018). It is important then that teachers pay attention to the possible difficulties of children when trying to solve critical reading activities in the classroom and devote more time to this type of activity. Moreover, we remark that the percentage of children successfully performing critical reading of graphs vary in the different graphs, this result provides the teacher with information related to those graphs that are more adequate to introduce children to critical reading of the same.

We also remark that in using the same maximum reading level in the different tasks that relate to various graphs we could compare the difficulty of reading these graphs at different reading levels by the children. The most difficult task was the pie chart, when considering the percentage of correct responses, since many children failed in proportional reasoning. Teachers should pay attention to the proportional reasoning of their students when asking them to work with a pie chart.

In summary our research complements the information from Alburquerque (2010), Canché (2009), Curcio (1987), Cruz (2013), Evangelista (2014), Fernándes and Morais (2011), and Pagan et al. (2008) with new types of tasks and a bigger sample of children from a different country. We hope this information is useful to teacher not only in Chile, and also to other teachers around the world to organize their teaching and help children to achieve a graphical literacy which is part of the statistical literacy needed in the modern world (Gal, 2002).

\section{ACKNOWLEDGEMENT}

Project EDU2016-74848-P (FEDER, AEI), Group FQM126 (Junta de Andalucía) and grant CONICYT PFCHA 72150306.

\section{Disclosure statement}

No potential conflict of interest was reported by the authors.

\section{Notes on contributors}

Danilo Díaz-Levicoy - Universidad Católica del Maule (UCM), Talca, Chile.

Carmen Batanero - University of Granada, Spain.

Pedro Arteaga - University of Granada, Spain.

María M. Gea - University of Granada, Spain.

\section{REFERENCES}

Albuquerque, R. G. C. (2010). Como adultos e crianças compreendem a escala representada em gráficos. Master Dissertation. Universidad Federal de Pernambuco.

Aoyama, K. (2007). Investigating a hierarchy of students' interpretations of graphs. International Electronic Journal of Mathematics Education, 2(3), 298-318.

Arteaga, P., Batanero, C., Contreras, J. M., \& Cañadas, G. (2012). Understanding statistical graphs: a research survey. BEIO, 28(3), 261-277.

Ávila, J., Fuenzalida, C., Jiménez, M., \& Ramírez, P. (2013). Matemática $5^{\circ}$ Básico. Santiago: Santillana.

Batanero, C., Díaz-Levicoy, D., \& Arteaga, P. (2018). Evaluación del nivel de lectura y la traducción de pictogramas por estudiantes chilenos de Educación Básica. Avances de Investigación en Educación Matemática, 14(1), 49-64.

Bertin, J. (1967). Semiologie graphique. Paris: Gauthier-Villars.

Canché, L. (2009). La comprensión gráfica de los alumnos del nivel primaria. Master Dissertation. Universidad Autónoma de Yucatán, México.

Charles, R., Caldwell, J., Cavanagh, M., Chancellor, D., Copley, J., Crown, W., .... Van de Walle, J. (2014). Matemática $3^{\circ}$ Educación Básica. Texto del estudiante. Santiago: Pearson.

Cruz, A. (2013). Erros e dificuldades de alunos de $1 .^{\circ}$ ciclo na representação de dados estatísticos Master Dissertation.. Universidad de Lisboa, Portugal. 
Curcio, F. R. (1981). The effect of prior knowledge, reading and mathematics achievement, and sex on comprehending mathematical relationships expressed in graphs (Ph.D. Dissertation), Brooklyn, NY: St. Francis College.

Curcio, F. R. (1987). Comprehension of mathematical relationships expressed in graphs. Journal for Research in Mathematics Education 18(5), 382-393. https://doi.org/10.2307/749086

Díaz-Levicoy, D., Batanero, C., Arteaga, P., \& Gea, M. M. (2016). Gráficos estadísticos en libros de texto de Educación Primaria: un estudio comparativo entre España y Chile. Bolema, 30(55), 713-737. https://doi.org/10.1590/1980-4415v30n55a20

Engel, J. (2019). Statistical literacy and society. What is civic statistics? En J. M. Contreras, M. M. Gea, M. M. López-Martín y E. Molina-Portillo (Eds.), Actas del Tercer Congreso International Virtual de Educación Estadística (pp. 1-17). Granada: Grupo de Investigación de Educación Estadística. Retrieved from https://www.ugr.es/ fqm126/civeest/ponencias/engel.pdf

Evangelista, B. (2014). Aprendendo a representar escalas em gráficos: um estudo de intervenção. Master Dissertation. Universidade Federal de Pernambuco, Brasil.

Fernándes, J. A., \& Morais, P. C. (2011). Leitura e interpretação de gráficos estatísticos por alunos do $9^{\circ}$ ano de escolaridade. Educação Matemática Pesquisa, 13(1), 95-115.

Freedman, E. G., \& Shah, P. (2002, April). Toward a model of knowledge-based graph comprehension. In M. Hegarty, B. Meyer, \& H. Narayanan (Eds). Proceedingo of the International Conference on Theory and Application of Diagrams (pp. 18-30). Springer, Berlin, Heidelberg. https://doi.org/10.1007/3-540-460373_3

Friel, S., Curcio, F., \& Bright, G. (2001). Making sense of graphs: critical factors influencing comprehension and instructional implications. Journal for Research in mathematics Education, 32(2), 124-158. https://doi.org/10.2307/749671

Gal, I. (2002). Adult's statistical literacy: Meaning, components, responsibilities. International Statistical Review, 70(1), 1-25. https://doi.org/10.1111/j.1751-5823.2002.tb00336.x

Konold, C., Higgins, T., Russell, S. J., \& Khalil, K. (2015). Data seen through different lenses. Educational Studies in Mathematics, 88(3), 305-325. https://doi.org/10.1007/s10649-013-9529-8

M.E.P. (2012). Programa de estudio matemáticas, I, II y III Ciclos de la educación general básica y ciclo diversificado. San José, Costa Rica: Ministerio de Educación Pública.

MEC. (2006). Real Decreto 1513/2006, de 7 de diciembre, por el que se establecen las enseñanzas mínimas correspondientes a la Educación Primaria. Madrid: MEC.

MINEDUC. (2012). Matemática Educación Básica. Bases curriculares. Santiago: Unidad de Currículum y Evaluación.

NCTM. (2000). Principles and standards for school mathematics. Reston, VA: Autor.

Neuendorf, K. A. (2016). The content analysis guidebook. London: Sage. https://doi.org/10.1002/9781118541555.wbiepc065

Pagan, A., \& Magina, S. (2011). O ensino de estatística na educação básica com foco na interdisciplinaridade: um estudo comparativo. Revista Brasileira de Estudos Pedagógicos, 92(232), 723-738.

Pagan, A., Leite, A. P., Magina, S., \& Cazorla, I. (2008). A leitura e interpretação de gráficos e tabelas no Ensino Fundamental e Médio. En V. Gitirana, F. Bellemain, \& V. Andrade (Eds.), Anais do $2^{\circ}$ Simpósio Internacional de Pesquisa em Educação Matemática (pp. 1-10). Recife: Universidad Federal de Pernambuco. https://doi.org/10.24109/2176-6681.rbep.92i232.675

Ridgway, J. (2016). Implications of the data revolution for statistics education. International Statistical Review, 84(3), 528-549. https://doi.org/10.1111/insr.12110

Shaughnessy, J. M., Garfield, J., \& Greer, B. (1996). Data handling. En A. J. Bishop, K. Clements, C. Keitel, J. Kilpatrick \& C. Laborde (Eds.), International handbook of mathematics education (pp. 205-237). Dordrecht, The Netherlands: Kluwer Academic Publishers. https://doi.org/10.1007/978-94-009-1465-0

Tufte, E. R. (2001). The visual display of quantitative information. Cheshire, CT: Graphics press. 